\title{
Levantamento do patrimônio geológico na "APA da Escarpa Devoniana" em Ponta Grossa, Sul do Brasil
}

\author{
Geoheritage survey at the 'Environmental Protection Area \\ (EPA) of the Devonian Escarpment' in Ponta Grossa, Southern \\ Brazil
}

\section{Recopilación del patrimonio geológico en el 'Área de Protección Ambiental (APA) de la Escarpa del Devónico' en Ponta Grossa, Sur de Brasil}

\author{
Maysa Folmann \\ https:/ / orcid.org/0000-0003-4165-356 \\ maysafolmann@gmail.com \\ Universidade Estadual de Ponta Grossa, UEPG, Ponta Grossa, PR
}

\begin{abstract}
Resumo: Os Campos Gerais do Paraná detêm um rico patrimônio geológico, atualmente ameaçado por conflitos socioambientais, sendo necessárias estratégias de geoconservação para protegê-lo. Este trabalho apresenta uma das etapas essenciais de geoconservação, o levantamento de sítios para o inventário do patrimônio geológico. O estudo é aplicado à Área de Proteção Ambiental (APA) da Escarpa Devoniana dentro dos limites do município de Ponta Grossa. Esta unidade de conservação engloba parte dos Campos Gerais e apresenta conflitos em relação ao uso e ocupação do território, levando à degradação de elementos geológicos importantes da região. É aqui apresentado o levantamento de 60 sítios potenciais para o inventário, sendo reconhecidas as suas principais características, recomendados os tipos de utilização para cada sítio, além de definidas categorias de interesse para nortear etapas seguintes de geoconservação.

Palavras-chave: geoconservação, unidade de conservação, Campos Gerais do Paraná

Abstract: This paper presents a geological heritage survey of the 'Environmental Protection Area (EPA) of the Devonian Escarpment' within the boundaries of Ponta Grossa (Southern Brazil), a region of notable geodiversity where socio-environmental conflicts are aggravated. The EPA is a conservation unit that embraces part of the Campos Gerais do Paraná, a rich geodiversity area that holds the last remnants of natural grasslands of the region. Consisting of the primordial stage of a geoconservation strategy, the survey for the inventory becomes an important tool to affect the geoheritage protection. Sixty geological interest sites are presented with their main features, use recommendations, and were classified in geological thematic categories. These actions can guide the next steps for geoconservation of this special area.
\end{abstract}

Keywords: geoconservation, conservation unit, Campos Gerais do Paraná 
Resumen: Este artículo presenta una encuesta del patrimonio geológico del 'Área de Protección Ambiental (APA) de la Escarpa del Devónico' dentro de los límites de Ponta Grossa (sur de Brasil), región de notable geodiversidad donde conflictos socioambientales se agravan. La APA es una unidad de conservación que incluye parte de los Campos Gerais do Paraná, un área de rica geodiversidad que aloja los últimos ejemplares de campos nativos de la región. Consistiendo en la etapa primordial de una estrategia de geoconservación, el levantamiento para el inventario se hace un importante instrumento para efectivar la protección del patrimonio geológico. Se presenta una recopilación de sesenta lugares de interés geológico con sus principales características, recomendaciones de uso y clasificados en categorías de interés para guiar los siguientes pasos para la geoconservación.

Palabras clave: geoconservación, unidad de conservación, Campos Gerais do Paraná.

\section{INTRODUÇÃO}

São tempos de angústia tratando-se da conservação da Natureza e do futuro das áreas naturais protegidas no Brasil. Sob as atuais perspectivas políticas do país, os recursos da natureza são vistos apenas como matéria-prima e a sua proteção como um empecilho para o desenvolvimento econômico. Sob o governo vigente, os retrocessos socioambientais são alarmantes e a atuação do Ministério de Meio Ambiente (MMA) mergulha em uma irresponsabilidade ambiental sem precedentes ${ }^{1}$.

Pela Constituição Federal (Brasil, 1988) é garantido ao cidadão o "direito ao meio ambiente ecologicamente equilibrado, bem de uso comum do povo e essencial à sadia qualidade de vida (...)". Entretanto, além de reconhecido este direito é necessário que existam instrumentos para concretizá-lo. Cabe então ao poder público o encargo de definir os espaços territoriais a serem especialmente protegidos.

A preocupação em proteger o meio ambiente remonta ao período colonial do Brasil e desde então foram criados diversos espaços de proteção à natureza, com objetivos e restrições distintas. Porém, apenas no ano 2000 parte destas áreas foram integralizadas em um sistema único, através da Lei $\mathrm{n}^{\circ} 9.985$ que instituiu o Sistema Nacional de Unidades de Conservação na Natureza (SNUC), que estabelece critérios e normas para criação, implantação e gestão das Unidades de Conservação (UCs).

Entre os objetivos das UCs está a proteção da diversidade dos ecossistemas do país, incluindo o resguardo de características relevantes de natureza geológica, os elementos da geodiversidade, ainda que geralmente estes elementos não sejam levados em consideração na criação e gestão das UCs (Brasil, 2000). O enfoque dado direciona-se muito mais à preservação da biodiversidade e, entretanto, os elementos e processos geológicos determinam, condicionam e sustentam a vida na Terra. Faz-se necessário, então, que o conhecimento acerca da geodiversidade chegue à toda a sociedade para a efetiva consecução de políticas púbicas para sua conservação. Assim, a geoconservação se apresenta como fator imprescindível na proteção do meio ambiente.

1 Passarinho, N. (2019). Como política ambiental de Bolsonaro afetou imagem do Brasil em 2019 e quais as consequências disso. Recuperado de https://www.bbc.com/portuguese/brasil-50851921 
Portanto, o objetivo deste trabalho é destacar a importância de estratégias de geoconservação em UCs, tendo como estudo de caso a Área de Preservação Ambiental (APA) da Escarpa Devoniana, a maior UC do estado do Paraná, que compreende um valioso patrimônio natural e cultural destacado por sua geodiversidade, e que passa por sérios conflitos socioambientais. É apresentada uma proposta de inventário do patrimônio geológico da APA nos limites de Ponta Grossa, município em que os conflitos se agravam constantemente (ver Oliveira 2014, no caso do Parque Nacional dos Campos Gerais e Mochiutti \& Guimarães 2018, no caso da APA da Escarpa Devoniana).

\section{APA DA ESCARPA DEVONIANA}

Considerada uma UC de uso sustentável, a Área de Proteção Ambiental (APA) da Escarpa Devoniana é a maior UC do estado do Paraná, tendo sido criada em 1992 por decreto do governo estadual. O objetivo de sua criação é de assegurar

[...] a proteção do limite natural entre o Primeiro e o Segundo Planaltos Paranaenses, inclusive faixa de Campos Gerais, que se constituem em ecossistema peculiar que alterna capões da floresta de araucária, matas de galerias e afloramentos rochosos, além de locais de beleza cênica como os "canyons" e de vestígios arqueológicos e pré-históricos (Paraná, 1992).

O limite natural configura-se numa imponente estrutura de relevo, a escarpa, que no Paraná representa um degrau topográfico com paredes abruptas e verticais, separando o Primeiro Planalto, a leste, e o Segundo Planalto, a oeste, englobando parte do território de 12 municípios de norte a sul do estado.

Equivocadamente, a escarpa leva o nome 'Devoniana' por ser sustentada por rochas da Formação Furnas, uma unidade geológica da bacia do Paraná de idade Siluro-devoniana, o que corresponde a cerca de 400 milhões de anos. Entretanto, a feição geomorfológica é muito mais nova, visto que sua formação se deu a partir do Mesozoico (Melo, Moro, \& Guimarães, 2007), algo como 150 milhões de anos atrás. A origem e a evolução da escarpa estão relacionadas aos processos geodinâmicos iniciados com a abertura do Oceano Atlântico e continuados processos erosivos associados a condições climáticas muito diferentes das de hoje.

Todos estes processos ocorridos ao longo do tempo geológico configuram a Escarpa Devoniana como uma espetacular feição da natureza, reconhecida como um patrimônio geológico nacional, estando cadastrado no sistema de Sítios Geológicos e Paleobiológicos do Brasil como SIGEP 80 (Souza \& Souza, 2002). Suas características físicas condicionam diferentes aspectos de relevo e hidrografia, favorecendo paisagens de grande beleza cênica e ecossistemas singulares, como os Campos Gerais, contemplados em parte no decreto de criação da APA da Escarpa Devoniana. 


\section{OS CAMPOS GERAIS DO PARANÁ}

Os Campos Gerais são um setor do Segundo Planalto Paranaense, definido pelo naturalista Maack (1948) como uma zona fitogeográfica, com o predomínio de campos limpos e matas galerias de floresta ombrófila mista. Ocupam uma faixa de quase $12.000 \mathrm{~km}^{2}$ e representam uma região de beleza única por suas paisagens que associam uma especial diversidade de elementos bióticos e abióticos a um rico patrimônio cultural.

A região denominada Campos Gerais apresenta definições diversas e impermanentes, "atendendo a necessidades e conveniências de uma identificação regional dentro de um estado com marcante dinâmica territorial nas últimas décadas" (Melo, Moro, \& Guimarães, 2007, p. 18). A identidade histórica e cultural dos Campos Gerais foi determinada intrinsecamente por fatores geológicos e geomorfológicos, com registros tão antigos que remontam à pré-história. A existência de diversos sítios arqueológicos na região foi propiciada pela ocorrência de abrigos naturais em rocha (lapas). Os sítios apresentam vestígios de populações indígenas nômades que passavam pela região em trilhas ramificadas do Caminho de Peabiru, que ligava o litoral do sul do país ao Pacífico (Parellada, 2007).

O início do movimento tropeiro no século XVIII foi um fenômeno econômico e sociocultural que conectou o sul do país aos centros econômicos e deu origem à maioria dos municípios dos Campos Gerais. As condições de relevo e hidrografia permitiram a condução dos animais de carga pelo caminho conhecido como Rota dos Tropeiros. Assim, a geodiversidade fez-se determinante no surgimento de vilas e cidades e influenciou a cultura local (Cassol \& Liccardo, 2013; Liccardo \& Piekarz, 2017).

Por seu rico patrimônio natural e cultural, a região dos Campos Gerais foi prioridade nas ações de resguardo e proteção, contando com a criação de diferentes áreas protegidas. Além da APA, outras UCs encontram-se na região como florestas e parques estaduais, nacionais e também reservas particulares do patrimônio natural ${ }^{2}$.

\section{CONFLITOS NA APA DA ESCARPA DEVONIANA}

Por ser uma unidade de conservação de uso sustentável, a APA da Escarpa Devoniana admite ocupação e exploração dos recursos naturais, trazendo no seu decreto a obrigação de se estabelecer um conjunto de zonas com atividades permitidas, restringidas e proibidas (Paraná, 1992), o que ocorreu apenas em 2004, ano em que foi elaborado seu Plano de Manejo. Apenas em 2013 seu conselho gestor foi formado e através de manobras políticas, atualmente uma composição desequilibrada privilegia setores privados ligados ao uso da terra. O Ministério Público do Paraná (MPPR) recomendou uma revisão deste conselho e estabelecimento de uma composição mais paritária junto ao então IAP (Instituto Ambiental do Paraná), hoje incorporado ao Instituto Água e Terra.

2 Consultar http://www.iap.pr.gov.br/paginas-80.html; https://www.icmbio.gov.br/portal/unidadesdeconservacao/ biomas-brasileiros/mata-atlantica/unidades-de-conservacao-mata-atlantica 
Com o atraso destas ações fundamentais, verifica-se uma profunda degradação do patrimônio natural pelo acúmulo de práticas indevidas dos setores agrossilvipastoril e da mineração, configurando uma gestão territorial desordenada. Recentemente, os conflitos acerca do uso inadequado dos recursos naturais se tornaram ainda mais evidentes com o projeto de lei que previa a redução da Unidade. De autoria do legislativo estadual, o PL$527 / 2016$ ameaçava alterar os limites da APA, reduzindo em $68 \%$ o seu tamanho original. O projeto demonstrava, além de inúmeras falhas técnicas e legais (Pontes, Massuqueto, Guimarães, \& Rocha, 2018), a falta de compreensão do conceito de uma UC de uso sustentável. Em resposta ao projeto, um movimento iniciado nos meios de comunicação desencadeou debates e divulgação de temas ambientais e científicos para toda população, e freou o trâmite do PL-527/ 2016 (Mochiutti \& Guimarães, 2018).

A importância da UC para a sociedade vai além da proteção de sítios naturais, podendo gerar benefícios por meio de serviços ambientais, renda através do turismo e arrecadação do ICMS Ecológico, como destacam Guimarães, Rocha, Moro e Liccardo (2017). O cenário atual retrata uma visão simplista de desenvolvimento econômico, que desconsidera a participação dos sistemas naturais preservados, negligenciando os valores da geodiversidade da APA da Escarpa Devoniana.

\section{GEODIVERSIDADE DA APA}

Tratando-se de iniciativas de conservação, destaca-se mais a proteção da biodiversidade em detrimento da geodiversidade. Entretanto, para a subsistência da fauna e da flora é imprescindível que se conserve o que as sustenta, a geodiversidade. A vida na Terra é consequência direta da evolução da diversidade abiótica, através de processos e eventos geológicos que possibilitaram as condições para sua existência. Neste trabalho, é considerada a definição de Gray (2013), que caracteriza a geodiversidade como a variedade natural de feições geológicas (rochas, minerais, fósseis), geomorfológicas (formas de relevo, processos), de solos e hidrológicas.

A região da APA da Escarpa Devoniana abrange uma excepcional geodiversidade, destacada por aspectos geológicos como várias seções-tipo da Bacia do Paraná, incluindo raras exposições de sequências antigas da bacia e registros fossilíferos. As feições geomorfológicas são diversas e compreendem escarpamentos, cânions, cachoeiras, corredeiras, além de especial relevo ruiniforme, furnas, sumidouros e cavernas, caracterizando uma espetacular paisagem cárstica desenvolvida em rochas areníticas da Formação Furnas. Determinantes na identidade original da região (pela vegetação campestre), os solos dos Campos Gerais constituem um importante elemento na produção agropecuária. 


\section{GEOCONSERVAÇÃO E PATRIMÔNIO GEOLÓGICO DA APA - LEVANTAMENTO PRELIMINAR EM PONTA GROSSA}

O termo Geoconservação foi empregado por Sharples (1993), designando o propósito de manter a geodiversidade de feições e sistemas da Terra, permitindo que seus processos em curso continuem a funcionar e evoluir de maneira natural. Desde então, as ações e estratégias para a geoconservação vêm sendo formuladas para atender os elementos da geodiversidade. Assim, são destacados os principais objetivos da geoconservação segundo Sharples (2002):

Conservar e assegurar a manutenção da geodiversidade; proteger e manter a integridade dos locais com relevância em termos de geoconservação; minimizar os impactos adversos dos locais importantes em termos de geoconservação; interpretar a geodiversidade para os visitantes de áreas protegidas; contribuir para a manutenção dos processos ecológicos dependentes da geodiversidade.

Para Brilha (2005), a geoconservação em sentido restrito, abrange apenas a conservação de certos elementos da geodiversidade com evidentes e significativos valores. Locais que apresentem um ou mais destes elementos, bem delimitados geograficamente, são denominados geossítios. Assim, a ocorrência de um conjunto de geossítios compõe o que se define como patrimônio geológico de uma região (Brilha, 2005).

Este trabalho apresenta uma proposta de inventário do patrimônio geológico, considerado o primeiro passo de uma estratégia sequenciada da Geoconservação determinada por Brilha (2005). O autor apresenta seis etapas: o inventário, quantificação, enquadramento legal, conservação, valorização e divulgação, e por fim, monitoramento do patrimônio geológico. O passo inicial do inventário consiste na identificação de potenciais sítios que possuam interesse geológico. Esta etapa enquadra-se no que Sharples (2002) designa como inventário de reconhecimento, parte de uma abordagem estratégica onde é feito um levantamento sistemático de locais significativos a serem conservados.

O levantamento foi aplicado à APA da Escarpa Devoniana, nos limites municipais de Ponta Grossa (Fig. 1), o qual é cenário de fascinantes paisagens com abundantes elementos da geodiversidade (furnas, cachoeiras, formas peculiares de relevo, dentre outros). Por estes atributos, o município apresenta grande potencial para atividades de turismo natural, entretanto nele se concentram os conflitos acerca do uso desordenado de seus recursos, e é um dos municípios que perderiam quase totalmente o território da APA pelo PL-527/ 2016 (Pontes, Massuqueto, Guimarães, \& Rocha, 2018). 
Figura 1. Mapa de localização da APA nos limites do município de Ponta Grossa, PR.

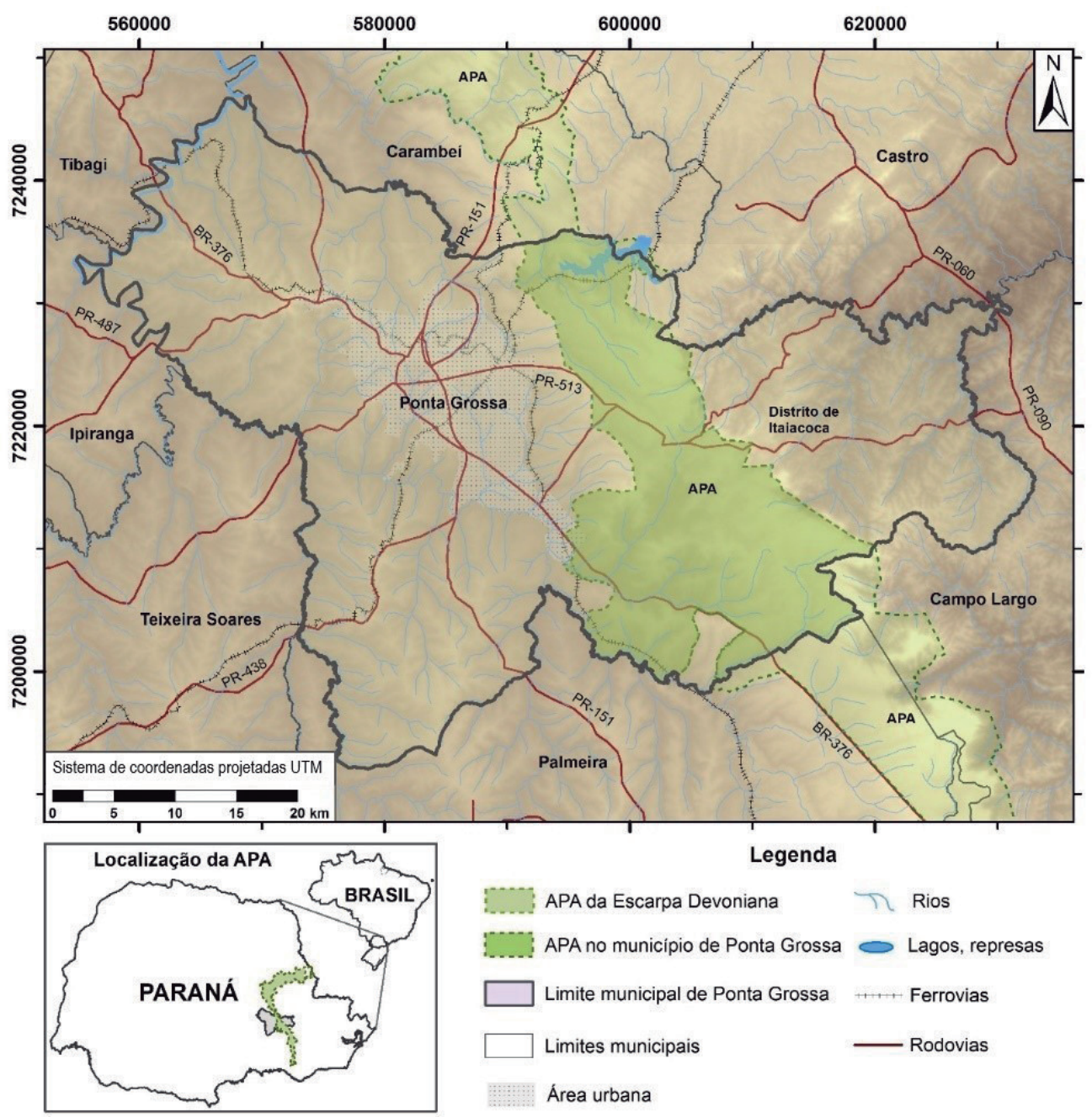

Fonte: elaborado a partir de IBGE, 2010.

A geodiversidade do município surge pelo seu especial contexto geológico, que engloba porções do embasamento, como o Complexo Granítico Cunhaporanga e o Grupo Itaiacoca, além de unidades litoestratigráficas da Bacia do Paraná, destacando-se a Formação Furnas. A evolução tectônica (em especial relacionada ao Arco de Ponta Grossa), estruturas sedimentares, ocorrências fossilíferas, sistema cárstico em rochas siliciclásticas e feições geomorfológicas peculiares são aspectos marcantes da geodiversidade da região, evidenciados em sítios geológicos. Estes locais foram selecionados e compõem o levantamento apresentado a seguir.

A seleção dos sítios foi realizada através de consulta bibliográfica, aos especialistas das Geociências, à comunidade local e caminhamentos prévios. Neste levantamento há sessenta sítios potenciais, espacializados e numerados no mapa da Figura 2, enquanto a Tabela 1, de forma complementar, sintetiza os dados referentes aos sítios, com nome, localização em coordenadas no sistema de projeção Universal Transverse Mercator (UTM), localidade e unidade geológica. 
Figura 2. Mapa geológico da APA nos limites de Ponta Grossa - PR.

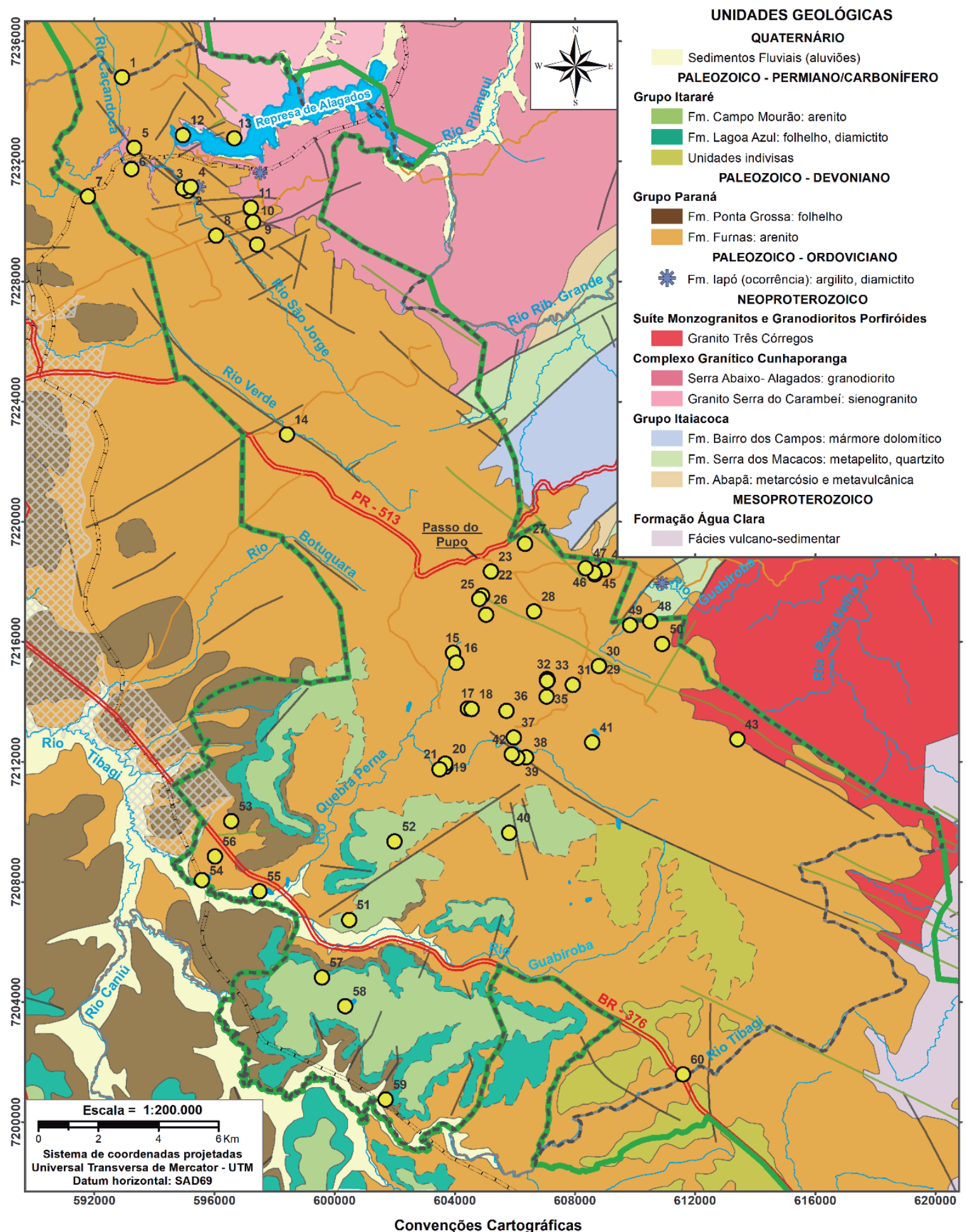

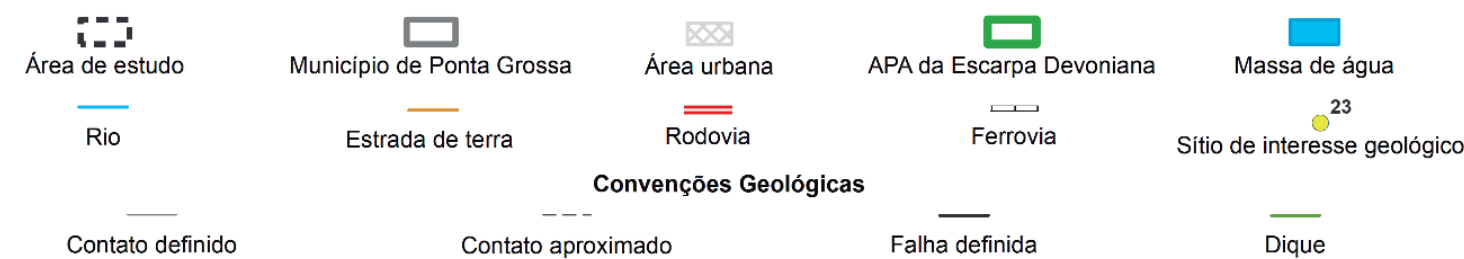

Fonte: modificado de MINEROPAR (2006a, 2006b) e Trzaskos, Vesely, \& Rostirolla (2006). 
Tabela 1. Nome, localização e unidade geológica pertence aos sítios pré-selecionados, complementar ao mapa geológico apresentado acima.

\begin{tabular}{|c|c|c|c|c|c|}
\hline \multirow{2}{*}{$\mathbf{N}^{0}$} & \multirow{2}{*}{ Nome } & \multicolumn{2}{|c|}{ Localização UTM } & \multirow{2}{*}{ Localidade } & \multirow{2}{*}{$\begin{array}{l}\text { Unidade } \\
\text { Geológica }\end{array}$} \\
\hline & & Coord. X & Coord. Y & & \\
\hline 1 & Cachoeira do Bandido & $592909 \mathrm{E}$ & $7234801 \mathrm{~S}$ & Rio Caçandoca & Furnas \\
\hline 2 & Cânion do rio São Jorge & $595112 \mathrm{E}$ & $7231016 \mathrm{~S}$ & Alagados & $\begin{array}{l}\text { Cunhaporanga/ } \\
\text { Iapó/Furnas }\end{array}$ \\
\hline 3 & Caverna do Opilião & $594954 \mathrm{E}$ & $7231101 \mathrm{~S}$ & Rio São Jorge & Furnas \\
\hline 4 & Caverna da Chaminé & $595158 \mathrm{E}$ & 7231165 S & Rio São Jorge & Furnas \\
\hline 5 & Abrigo Usina São Jorge & $593010 \mathrm{E}$ & $7232307 \mathrm{~S}$ & Alagados & Furnas \\
\hline 6 & Abrigo Rio Pitangui I & $593016 \mathrm{E}$ & $7231821 \mathrm{~S}$ & Alagados & Furnas \\
\hline 7 & Cachoeira da $1^{\mathrm{a}}$ Ponte & $591794 \mathrm{E}$ & $7230829 \mathrm{~S}$ & Alagados & Furnas \\
\hline 8 & Ponte do rio São Jorge & $596062 \mathrm{E}$ & $7229532 \mathrm{~S}$ & Rio São Jorge & Furnas \\
\hline 9 & Fenda dos Tonini & $597422 \mathrm{E}$ & 7229233 S & próximo à Serrinha Alagados & Furnas \\
\hline 10 & Boulder Tetinho & $597283 \mathrm{E}$ & $7229987 \mathrm{~S}$ & Alagados & Furnas \\
\hline 11 & Caverna do Bugio & $597210 \mathrm{E}$ & $7230461 \mathrm{~S}$ & Setor Vale dos Tucanos & Furnas \\
\hline 12 & Pedra do Pulo & $594947 \mathrm{E}$ & $7232877 \mathrm{~S}$ & Alagados & $\begin{array}{l}\text { Cunhaporanga/ } \\
\text { Furnas }\end{array}$ \\
\hline 13 & Morro da Santa & $596661 \mathrm{E}$ & $7232774 \mathrm{~S}$ & Alagados & Furnas \\
\hline 14 & Capão da Onça & $598409 \mathrm{E}$ & $7222904 \mathrm{~S}$ & Itaiacoca & Furnas \\
\hline 15 & Furna do Buraco do Padre & $603946 \mathrm{E}$ & 7215633 S & Itaiacoca & Furnas \\
\hline 16 & Fenda da Freira & $604055 \mathrm{E}$ & $7215300 \mathrm{~S}$ & próximo Buraco do Padre & Furnas \\
\hline 17 & Setor Macarrão & $604432 \mathrm{E}$ & $7213780 \mathrm{~S}$ & próximo Buraco do Padre & Furnas \\
\hline 18 & Gruta Macarrão & $604563 \mathrm{E}$ & $7213761 S$ & Setor de escalada Macarrão & Furnas \\
\hline 19 & Sumidouro do rio Quebra-Perna & $603685 \mathrm{E}$ & $7211839 S$ & Fazenda Cristalina & Furnas \\
\hline 20 & Abrigo Quebra-Perna 1 & $603676 \mathrm{E}$ & 7211935 S & Fazenda Cristalina & Furnas \\
\hline 21 & Abrigo Quebra-Perna 2 & $603496 \mathrm{E}$ & $7211756 \mathrm{~S}$ & Fazenda Cristalina & Furnas \\
\hline 22 & Furnas Gêmeas 1 & $605203 \mathrm{E}$ & $7218341 \mathrm{~S}$ & Passo do Pupo & Furnas \\
\hline 23 & Furnas Gêmeas 2 & $605203 \mathrm{E}$ & $7218341 \mathrm{~S}$ & Passo do Pupo & Furnas \\
\hline 24 & Furna Anfiteatro & $604904 \mathrm{E}$ & 7217532 S & Passo do Pupo & Furnas \\
\hline 25 & Furna Grande & $604817 \mathrm{E}$ & 7217422 S & Passo do Pupo & Furnas \\
\hline 26 & Sumidouro Córrego das Fendas & $605043 \mathrm{E}$ & 7216905 S & Passo do Pupo & Furnas \\
\hline 27 & Pedra Solteira & $606339 \mathrm{E}$ & 7219262 S & Passo do Pupo & Furnas \\
\hline 28 & Furna RPPN Paiquerê & $606636 \mathrm{E}$ & 7217013 S & Itaiacoca & Furnas \\
\hline 29 & Dolina do Matador & $608805 \mathrm{E}$ & $7215189 S$ & Cerradinho - Fazenda Tayná & Furnas \\
\hline 30 & Poço das Andorinhas & $608796 \mathrm{E}$ & $7215192 S$ & Cerradinho - Fazenda Tayná & Furnas \\
\hline 31 & Caverna dos 300 & $607930 \mathrm{E}$ & $7214561 \mathrm{~S}$ & Cerradinho - Fazenda Sapê & Furnas \\
\hline 32 & Fenda Sem Fim & $607075 \mathrm{E}$ & 7214755 S & Fazenda Cercado Grande & Furnas \\
\hline 33 & Abismo da Bromélia & $607097 \mathrm{E}$ & $7214722 \mathrm{~S}$ & Fazenda Cercado Grande & Furnas \\
\hline 34 & Abismo da Brisa & $607080 \mathrm{E}$ & $7214700 \mathrm{~S}$ & Fazenda Cercado Grande & Furnas \\
\hline 35 & Fenda dos Guacharos & $607062 \mathrm{E}$ & $7214177 \mathrm{~S}$ & Fazenda Cercado Grande & Furnas \\
\hline 36 & Afloramento Sapelí & $605725 \mathrm{E}$ & $7213700 \mathrm{~S}$ & Itaiacoca & Furnas \\
\hline 37 & Sumidouro da Mariquinha & $605969 \mathrm{E}$ & $7212814 S$ & Fazenda Conquista & Furnas \\
\hline 38 & Cachoeira da Mariquinha & $606375 \mathrm{E}$ & $7212146 \mathrm{~S}$ & Fazenda Conquista & Furnas \\
\hline 39 & Abrigo Cambiju PR PG 2 & $606082 \mathrm{E}$ & $7212134 \mathrm{~S}$ & Fazenda Conquista & Furnas \\
\hline 40 & Toquinhas & $605816 \mathrm{E}$ & 7209638 S & Fazenda Rivadávia & Campo Mourão \\
\hline
\end{tabular}




\begin{tabular}{|c|c|c|c|c|c|}
\hline \multirow{2}{*}{$\mathbf{N}^{\mathbf{0}}$} & \multirow{2}{*}{ Nome } & \multicolumn{2}{|c|}{ Localização UTM } & \multirow{2}{*}{ Localidade } & \multirow{2}{*}{$\begin{array}{l}\text { Unidade } \\
\text { Geológica }\end{array}$} \\
\hline & & Coord. X & Coord. Y & & \\
\hline 41 & Morro do Castelo PR PG 2 & $608572 \mathrm{E}$ & $7212650 \mathrm{~S}$ & Itaiacoca & Furnas \\
\hline 42 & Abrigo Cambiju PR PG 1 & $605900 \mathrm{E}$ & $7212250 \mathrm{~S}$ & Fazenda Conquista & Furnas \\
\hline 43 & Cachoeira do Perau & $613411 \mathrm{E}$ & $7212751 S$ & Fazenda Cambiju & Furnas \\
\hline 44 & Mosteiro & $608840 \mathrm{E}$ & 7218333 S & Cerradinho & Frunas \\
\hline 45 & Fenda Santa Maria I & $608656 \mathrm{E}$ & $7218251 \mathrm{~S}$ & $\begin{array}{l}\text { Cerradinho - Chácara Sta } \\
\text { Maria }\end{array}$ & Furnas \\
\hline 46 & Fenda Santa Maria II & $608640 \mathrm{E}$ & $7218288 \mathrm{~S}$ & $\begin{array}{l}\text { Cerradinho - Chácara Sta } \\
\text { Maria }\end{array}$ & Furnas \\
\hline 47 & Caverna das Andorinhas & $608354 \mathrm{E}$ & $7218451 \mathrm{~S}$ & Cerradinho - Fazenda Tayná & Furnas \\
\hline 48 & Filito da encruzilhada & $610502 \mathrm{E}$ & 7216685 S & Fazenda Cambiju & Itaiacoca \\
\hline 49 & Afloramento Lunar & $609840 \mathrm{E}$ & 7216556 S & Fazenda Cambiju & Furnas \\
\hline 50 & Pedreira da Cambiju & $610905 \mathrm{E}$ & 7215924 S & Fazenda Cambiju & Furnas \\
\hline 51 & Arenitos do P.E. Vila Velha & $600488 \mathrm{E}$ & 7206734 S & Parque Estadual de Vila Velha & Campo Mourão \\
\hline 52 & Fortaleza & $601991 \mathrm{E}$ & 7209346 S & Parque Estadual de Vila Velha & Campo Mourão \\
\hline 53 & Furnas 1 e 2 do P.E. Vila Velha & $596561 \mathrm{E}$ & 7210024 S & Parque Estadual de Vila Velha & Furnas \\
\hline 54 & Lagoa Dourada & $595587 \mathrm{E}$ & 7208056 S & Parque Estadual de Vila Velha & Furnas \\
\hline 55 & Lagoa Tarumã & $597495 \mathrm{E}$ & 7207685 S & Parque Estadual de Vila Velha & Furnas \\
\hline 56 & Furna 4 do P.E. Vila Velha & $596012 \mathrm{E}$ & $7208850 \mathrm{~S}$ & Parque Estadual de Vila Velha & Furnas \\
\hline 57 & Arcos Fazenda Rivadávia & $599579 \mathrm{E}$ & 7204816 S & Fazenda Rivadávia & Campo Mourão \\
\hline 58 & Lagoa Fazenda Rivadávia & $600350 \mathrm{E}$ & 7203857 S & Fazenda Rivadávia & Furnas \\
\hline 59 & $\begin{array}{l}\text { Sítio fossilífero Fazenda } \\
\text { Rivadávia }\end{array}$ & $601699 \mathrm{E}$ & 7200752 S & Fazenda Rivadávia & Lagoa Azul \\
\hline 60 & Cânion Cabeceiras do rio Tibagi & $611601 \mathrm{E}$ & 7201589 S & BR-376 entre Grossa/Palmeira & Furnas \\
\hline
\end{tabular}

Dentre os sítios selecionados, alguns apresentam nomes já consagrados na região como o Buraco do Padre, enquanto outros, menos conhecidos, receberam denominações segund o o conhecimento da população local, a exemplo da Pedra Solteira, também conhecida por frequentadores como Pedra Solitária. Sítios ainda não descritos e sem nome conhecido foram nomeados neste levantamento, como o Afloramento Lunar.

Os locais concentram-se na área norte, região da Represa de Alagados e na área central, região do vilarejo Passo do Pupo, no distrito de Itaiacoca. Alguns dos sítios encontram-se no Parque Estadual de Vila Velha, outros em propriedades particulares, estando a maioria em processo de desapropriação relacionada à implantação do Parque Nacional dos Campos Gerais.

Quanto à classificação dos sítios em relação à unidade geológica em que se encontram, a grande maioria está localizada sobre a Formação Furnas, pertencente ao Grupo Paraná. Alguns pontos apresentam contato litológico entre a Formação Furnas e seu embasamento, como o Complexo Granítico Cunhaporanga. Outros pontos diferenciados são referentes à Formação Campo Mourão, unidade pertencente ao Grupo Itararé.

A Tabela 2 sintetiza os dados relacionados às características fundamentais dos sítios selecionados. Os critérios adotados levaram em consideração a utilização dos sítios pelo público, as categorias temáticas de interesse e feições relevantes da geodiversidade, e podem auxiliar na definição de estratégias subsequentes ao inventário. A definição de 
categorias temáticas auxilia na organização e tratamento dos dados coletados e é uma abordagem utilizada há tempos em iniciativas de inventariação (Wimbledon et al., 1999), sendo o conjunto de categorias temáticas a representação total da geodiversidade da área em estudo.

No que se refere ao tipo de uso dos sítios, foram determinadas quatro categorias de utilização - turística, científica, didática e esportiva. $\mathrm{O}$ uso turístico aqui adotado refere-se ao público que visita o sítio para lazer, a fim de usufruir dos elementos naturais, como um banho de cachoeira, ou contemplar uma bela vista da paisagem. O uso científico está relacionado a atividades de pesquisa desenvolvida por universidades e grupos independentes, assim como instituições a exemplo do serviço geológico do estado. Já o uso didático ou educativo é realizado pelas universidades, mas também por instituições de ensino básico, em atividades de estudo do meio natural. E por fim, a utilização esportiva contempla atividades de esporte ao ar livre, principalmente escalada em rocha.

Os sítios podem apresentar mais de um tipo de uso ou mesmo nenhum uso atual, mas com potencialidades de uso futuro, de maneira complementar. O Gráfico 1 sintetiza a relação de número de sítios e sua classificação quanto ao tipo de uso atualmente empregado, além do tipo de uso recomendado pelas suas feições de destaque.

A seleção dos sítios levou em consideração os diferentes aspectos da geodiversidade, assim foram identificados sítios de interesse estritamente geológico (com características relevantes quanto a estratigrafia, hidrogeologia, geologia sedimentar e estrutural), bem como sítios com notáveis aspectos geomorfológicos, espeleológicos e/ou paleontológicos. Da mesma forma, foram ponderados sítios relacionados ao patrimônio cultural, como locais de interesse arqueológico e histórico que se encontram na interface com o patrimônio geológico. Esta distribuição permitiu a identificação de oito categorias de uso potencial de interesse, sintetizadas no Quadro 1.

Por fim, são brevemente indicadas as feições de destaque mais importantes de cada sítio, abrangendo aspectos de diferentes escalas: desde a paisagem em si, como vistas panorâmicas excepcionais, até microfeições como espeleotemas singulares.

Tabela 2. Caracterização dos sítios referente à utilização, uso potencial de interesse e feições relevantes.

\begin{tabular}{|c|c|c|c|c|}
\hline $\mathbf{N}^{\mathbf{o}}$ & Nome do sítio & $\begin{array}{l}\text { Utilização atual/pré- } \\
\text { recomendada }\end{array}$ & $\begin{array}{l}\text { Uso potencial de } \\
\text { interesse (Sedimentar; } \\
\text { Estratigráfico; Espeleológico; } \\
\text { Geomorfológico; } \\
\text { Tectônico; Hidrogeológico; } \\
\text { Paleontológico; } \\
\text { Arqueológico) }\end{array}$ & Feição de destaque \\
\hline 1 & Cachoeira do Bandido & Turística & Sed & $\begin{array}{l}\text { Estratos, cachoeira, estruturas } \\
\text { sedimentares }\end{array}$ \\
\hline 2 & Cânion do rio São Jorge & $\begin{array}{l}\text { Turística/Científica/ } \\
\text { Esportiva/Didática }\end{array}$ & Tect/Est/Arq/Geom & $\begin{array}{l}\text { Falha, estratos, contatos, vestígios } \\
\text { arqueológicos, cachoeira }\end{array}$ \\
\hline 3 & Caverna do Opilião & Científica/Didática & Est/Esp/Paleo & Estratos, espeleotemas, icnofósseis \\
\hline 4 & Caverna da Chaminé & $\begin{array}{l}\text { Científica/Esportiva/ } \\
\text { Didática }\end{array}$ & Est/Esp & Estratos, espeleotemas \\
\hline 5 & Abrigo Usina São Jorge & $\begin{array}{l}\text { Turística/Científica/ } \\
\text { Didática }\end{array}$ & Arq & Vestígios arqueológicos \\
\hline
\end{tabular}


continuação

\begin{tabular}{|c|c|c|c|c|}
\hline $\mathbf{N}^{\mathbf{o}}$ & Nome do sítio & $\begin{array}{l}\text { Utilização atual/pré- } \\
\text { recomendada }\end{array}$ & $\begin{array}{l}\text { Uso potencial de } \\
\text { interesse (Sedimentar; } \\
\text { Estratigráfico; Espeleológico; } \\
\text { Geomorfológico; } \\
\text { Tectônico; Hidrogeológico; } \\
\text { Paleontológico; } \\
\text { Arqueológico) }\end{array}$ & Feição de destaque \\
\hline 6 & Abrigo Rio Pitangui I & $\begin{array}{l}\text { Turística/Científica/ } \\
\text { Didática }\end{array}$ & Arq & Vestígios arqueológicos \\
\hline 7 & Cachoeira da $1^{a}$ Ponte & Turística/Didática & Sed & $\begin{array}{l}\text { Cachoeira, estruturas } \\
\text { sedimentares }\end{array}$ \\
\hline 8 & Ponte do rio São Jorge & Turística/Didática & Sed & $\begin{array}{l}\text { Estruturas sedimentares, panelas, } \\
\text { marmitas }\end{array}$ \\
\hline 9 & Fenda dos Tonini & $\begin{array}{l}\text { Científica/Turística/ } \\
\text { Didática }\end{array}$ & Est & Estruturas sedimentares \\
\hline 10 & Boulder Tetinho & $\begin{array}{l}\text { Turística/Esportiva/ } \\
\text { Didática }\end{array}$ & Sed & Estruturas sedimentares \\
\hline 11 & Caverna do Bugio & Científica & Esp & Espeleotemas \\
\hline 12 & Pedra do Pulo & $\begin{array}{l}\text { Turística/Esportiva/ } \\
\text { Científica/Didática }\end{array}$ & Est & Estratos, contato geológico \\
\hline 13 & Morro da Santa & Turística/Esportiva & Est & Estratos, estruturas sedimentares \\
\hline 14 & Capão da Onça & Turística/Didática & Sed/Geom/Arq & $\begin{array}{l}\text { Estruturas sedimentares, } \\
\text { cachoeiras, vest. arqueológicos }\end{array}$ \\
\hline 15 & $\begin{array}{l}\text { Furna do Buraco do } \\
\text { Padre }\end{array}$ & $\begin{array}{l}\text { Turística/Científica/ } \\
\text { Didática }\end{array}$ & Tect/Geom/Hidro/Esp & $\begin{array}{l}\text { Falhas, furnas, cachoeiras, } \\
\text { sumidouros, dutos de dissolução }\end{array}$ \\
\hline 16 & Fenda da Freira & Científica & Est/Geom & Fenda, estratos, espeleotemas \\
\hline 17 & Setor Macarrão & $\begin{array}{l}\text { Turística/Esportiva/ } \\
\text { Científica/Didática }\end{array}$ & Sed/Tect/Arq & $\begin{array}{l}\text { Estratos, est. sedimentares, falhas, } \\
\text { vest. arqueológicos }\end{array}$ \\
\hline 18 & Gruta Macarrão & Científica & Tect & Fenda \\
\hline 19 & $\begin{array}{l}\text { Sumidouro rio Quebra- } \\
\text { Perna }\end{array}$ & $\begin{array}{l}\text { Turística/Científica/ } \\
\text { Didática }\end{array}$ & $\begin{array}{l}\text { Geom/Hidro/Tect/Esp/ } \\
\text { Paleo }\end{array}$ & $\begin{array}{l}\text { Cachoeiras, sumidouro, fenda, } \\
\text { espeleotemas, icnofósseis }\end{array}$ \\
\hline 20 & Abrigo Quebra-Perna 1 & $\begin{array}{l}\text { Turística/Científica/ } \\
\text { Didática }\end{array}$ & Arq & Vestígios arqueológicos \\
\hline 21 & Abrigo Quebra-Perna 2 & $\begin{array}{l}\text { Turística/Científica/ } \\
\text { Didática }\end{array}$ & Arq & Vestígios arqueológicos \\
\hline 22 & Furnas Gêmeas 1 & $\begin{array}{l}\text { Turística/Científica/ } \\
\text { Didática }\end{array}$ & Geom/Tect/Esp & Furna, falha, espeleotemas \\
\hline 23 & Furnas Gêmeas 2 & $\begin{array}{l}\text { Turística/Científica/ } \\
\text { Didática }\end{array}$ & Geom/Tect/Esp/Paleo & $\begin{array}{l}\text { Furna, falha, bacia de dissolução, } \\
\text { alvéolos, icnofósseis }\end{array}$ \\
\hline 24 & Furna Anfiteatro & Científica/Didática & Geom/Tect & Furna, fenda \\
\hline 25 & Furna Grande & $\begin{array}{l}\text { Turística/Científica/ } \\
\text { Esportiva/Didática }\end{array}$ & Geom/Tect/Est/Esp/Paleo & $\begin{array}{l}\text { Furna, falhas, est. sedimentares, } \\
\text { espeleotemas, icnofósseis }\end{array}$ \\
\hline 26 & $\begin{array}{l}\text { Sumidouro córrego das } \\
\text { Fendas }\end{array}$ & Científica/Didática & Geom/Esp/Hidro/Paleo & Fenda, sumidouro, icnofósseis \\
\hline 27 & Pedra Solteira & $\begin{array}{l}\text { Turística/Esportiva/ } \\
\text { Didática }\end{array}$ & Geom/Sed & $\begin{array}{l}\text { Bloco "testemunho", estruturas } \\
\text { sedimentares }\end{array}$ \\
\hline 28 & Furna RPPN Paiquerê & Científica/Didática & Geom & Furna \\
\hline 29 & Dolina do Matador & Científica/Didática & Geom & Furna \\
\hline 30 & Poço das Andorinhas & Científica/Didática & Geom/Esp & Furna (forma funil invertido) \\
\hline 31 & Caverna dos 300 & Científica/Turística & Esp & Espeleotemas \\
\hline 32 & Fenda Sem Fim & Científica & Tect/Est/Arq & $\begin{array}{l}\text { Fenda, estruturas sedimentares, } \\
\text { vestígios arqueológicos }\end{array}$ \\
\hline 33 & Abismo da Bromélia & Científica & Geom & Furna \\
\hline 34 & Abismo da Brisa & Científica & Geom & Furna \\
\hline
\end{tabular}


conclusão

\begin{tabular}{|c|c|c|c|c|}
\hline $\mathbf{N}^{\mathbf{o}}$ & Nome do sítio & $\begin{array}{l}\text { Utilização atual/pré- } \\
\text { recomendada }\end{array}$ & $\begin{array}{l}\text { Uso potencial de } \\
\text { interesse (Sedimentar; } \\
\text { Estratigráfico; Espeleológico; } \\
\text { Geomorfológico; } \\
\text { Tectônico; Hidrogeológico; } \\
\text { Paleontológico; } \\
\text { Arqueológico) }\end{array}$ & Feição de destaque \\
\hline 35 & Fenda dos Guacharos & Científica & Geom/Tect & Fenda \\
\hline 36 & Afloramento Sapelí & Científica & Arq/Geom & Vestígios arqueológicos \\
\hline 37 & $\begin{array}{l}\text { Sumidouro da } \\
\text { Mariquinha }\end{array}$ & Científica & Tect/Hidro/Esp & $\begin{array}{l}\text { Fenda, sumidouro, alvéolos, dutos } \\
\text { de dissolução }\end{array}$ \\
\hline 38 & $\begin{array}{l}\text { Cachoeira da } \\
\text { Mariquinha }\end{array}$ & $\begin{array}{l}\text { Turística/Científica/ } \\
\text { Didática }\end{array}$ & Geom/Sed & $\begin{array}{l}\text { Cachoeira, estruturas } \\
\text { sedimentares }\end{array}$ \\
\hline 39 & $\begin{array}{l}\text { Abrigo Cambiju PR } \\
\text { PG } 2\end{array}$ & Turística/Científica & Arq & Vestígios arqueológicos \\
\hline 40 & Toquinhas & Científica/Didática & Geom/Sed & $\begin{array}{l}\text { Relevo ruiniforme, estruturas } \\
\text { sedimentares }\end{array}$ \\
\hline 41 & $\begin{array}{l}\text { Morro do Castelo PR } \\
\text { PG } 2\end{array}$ & Científica & Arq & Vestígios arqueológicos \\
\hline 42 & Abrigo Cambiju PR PG 1 & Científica & Arq & Vestígios arqueológicos \\
\hline 43 & Cachoeira do Perau & Turística/Esportiva & Geom & Cachoeira \\
\hline 44 & Mosteiro & Turística/Didática & Geom & $\begin{array}{l}\text { Visão panorâmica do } 1^{\circ} \text { e } 2^{\circ} \\
\text { planalto }\end{array}$ \\
\hline 45 & Fenda Santa Maria I & Científica/Didática & Tect/Sed/Paleo & Fenda, estratos, icnofósseis \\
\hline 46 & Fenda Santa Maria II & Científica/Didática & Tect/Paleo & Fraturas, icnofósseis \\
\hline 47 & Caverna das Andorinhas & Científica/Didática & Esp/Tect/Paleo & Espeleotemas, falha, icnofósseis \\
\hline 48 & Afloramento de filito & Científica & Est & Litologia, contato? \\
\hline 49 & Afloramento "lunar" & Científica & Sed/Tect & Estruturas sedimentares, falhas \\
\hline 50 & Pedreira da Cambiju & Científica & Sed/Tect & Estruturas sedimentares, falhas? \\
\hline 51 & Arenitos P.E. Vila Velha & $\begin{array}{l}\text { Turística/Científica/ } \\
\text { Didática }\end{array}$ & Sed/Geom & $\begin{array}{l}\text { Estruturas sedimentares, relevo } \\
\text { ruiniforme }\end{array}$ \\
\hline 52 & Fortaleza & $\begin{array}{l}\text { Turística/Científica/ } \\
\text { Didática }\end{array}$ & Sed/Geom & $\begin{array}{l}\text { Estruturas sedimentares, relevo } \\
\text { ruiniforme }\end{array}$ \\
\hline 53 & $\begin{array}{l}\text { Furnas } 1 \text { e } 2 \text { P.E. Vila } \\
\text { Velha }\end{array}$ & Turística/Didática & Hidro/Geom & Lagoa, furna \\
\hline 54 & Lagoa Dourada & $\begin{array}{l}\text { Turística/Científica/ } \\
\text { Didática }\end{array}$ & Hidro/Geom & Lagoa, furna \\
\hline 55 & Lagoa Tarumã & $\begin{array}{l}\text { Turística/Científica/ } \\
\text { Didática }\end{array}$ & Hidro/Geom & Lagoa, furna \\
\hline 56 & Furna 4 P.E. Vila Velha & Científica & Hidro/Geom & Lagoa, furna \\
\hline 57 & $\begin{array}{l}\text { Arcos Fazenda } \\
\text { Rivadávia }\end{array}$ & Científica & Sed/Geom/Arq & $\begin{array}{l}\text { Est. sedimentares, relevo } \\
\text { ruiniforme, vest. arqueológicos }\end{array}$ \\
\hline 58 & $\begin{array}{l}\text { Lagoa Fazenda } \\
\text { Rivadávia }\end{array}$ & Científica & Hidro/Geom & Lagoa, furna \\
\hline 59 & $\begin{array}{l}\text { Sítio fossilífero Faz } \\
\text { Rivadávia }\end{array}$ & Científica & Paleo & Fósseis \\
\hline 60 & $\begin{array}{l}\text { Cânion Cabeceiras rio } \\
\text { Tibagi }\end{array}$ & Turística & Geom & Cânion \\
\hline
\end{tabular}


Gráfico 1. Distribuição dos sítios classificados pela sua utilização.

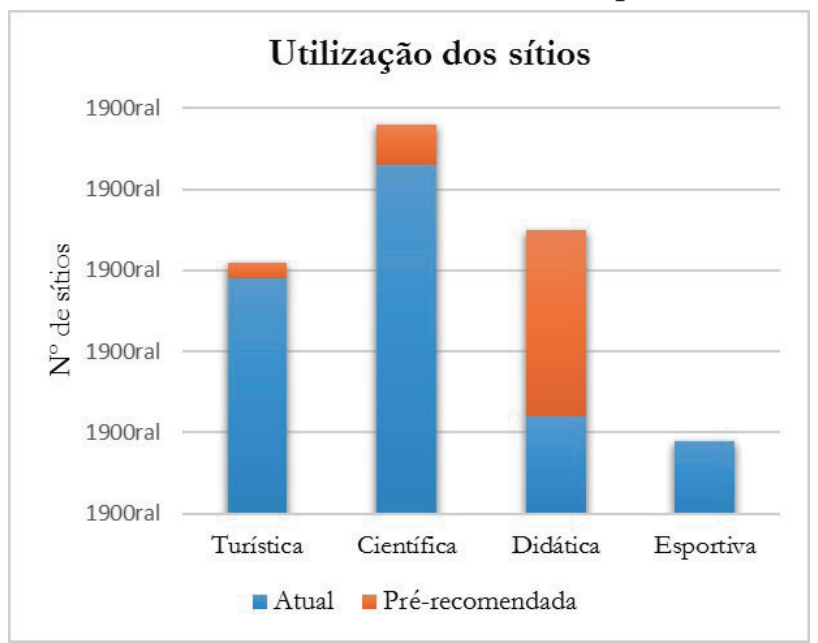

Quadro 1. Características principais das categorias temáticas.

\begin{tabular}{|l|l|}
\hline Categorias temáticas dos sítios \\
\hline Arqueologia & $\begin{array}{l}\text { Locais com vestígios da ocupação e passagem de antigas } \\
\text { populações da região, onde foram encontrados elementos } \\
\text { como artes rupestres ou materiais líticos. }\end{array}$ \\
\hline Espeleologia & $\begin{array}{l}\text { Locais com características que possibilitem a interpretação de } \\
\text { processos espeleogenéticos, em especial do carste em rochas } \\
\text { areníticas. }\end{array}$ \\
\hline Estratigrafia & $\begin{array}{l}\text { Locais com relações estratigráficas que permitam } \\
\text { interpretações de idades relativas e paleoambientais. Locais- } \\
\text { chave de contato entre unidades geológicas distintas. }\end{array}$ \\
\hline Geomorfologia & $\begin{array}{l}\text { Locais com formas diferenciais de relevo permitindo a } \\
\text { interpretação de processos geomorfológicos ou apresentem } \\
\text { uma visão privilegiada de unidades de relevo. }\end{array}$ \\
\hline Hidrogeologia & $\begin{array}{l}\text { Locais que permitem a interpretação de processos do ciclo } \\
\text { hidrológico, como dutos de dissolução e sumidouros. }\end{array}$ \\
\hline Paleontologia & $\begin{array}{l}\text { Locais com vestígios fósseis, que permitem a interpretação de } \\
\text { paleoambientes, como camadas sedimentares com a presença } \\
\text { de icnofósseis. }\end{array}$ \\
\hline Geologia Sedimentar & $\begin{array}{l}\text { Locais com estruturas sedimentares passíveis de interpretação } \\
\text { dos processos de acumulação de sedimentos e ambientes } \\
\text { característicos. }\end{array}$ \\
\hline $\begin{array}{l}\text { Geologia Estrutural e } \\
\text { Tectônica }\end{array}$ & $\begin{array}{l}\text { Locais com estruturas formadas por processos tectônicos } \\
\text { ocorridos na região ou evidenciem o controle estrutural na } \\
\text { formação de feições como cavidades e cânions. }\end{array}$ \\
\hline
\end{tabular}

\section{DISCUSSÃO}

Para o levantamento de sítios do patrimônio geológico, foram catalogados 60 locais com feições e atrativos diversos como furnas, cachoeiras, cavernas, abrigos sob rocha, lagoas, paredes rochosas, mirantes, fendas e cânions. Os sítios são representantes significativos da geodiversidade da APA da Escarpa Devoniana em Ponta Grossa, entretanto o processo de inventário é dinâmico, sendo sua atualização regular uma tarefa necessária. Novos locais podem ser incorporados, assim como outros podem ser excluídos. 
Em relação à localização concentrada dos sítios nas regiões de Alagados e Passo do Pupo, pode-se supor que a facilidade de acesso seja um fator determinante. A região da represa de Alagados apresenta vias de acesso variadas e é procurada por praticantes de motocross, mountain bike, caminhada e corrida. O vilarejo do Passo do Pupo também se apresenta como um centro a partir do qual bifurcam-se estradas e caminhos que dão acesso aos principais sítios da região. Porém, o potencial para descoberta de novos sítios na área de estudo é grande, sendo dificultado pelo acesso escasso ou inexistente para muitos deles. Outro ponto a ser salientado é a restrição de entrada por parte de alguns proprietários, fazendo com que sítios importantes sejam inacessíveis.

A classificação dos sítios considerando seu uso atual foi importante para saber como os sítios estão sendo e como poderiam ser melhor utilizados. Sendo possível fazer recomendações de uso a serem estudadas em novos trabalhos.

Dentre os usos dos sítios, destaca-se o científico. Pôde-se observar que grande parte destes locais é constituída por algum tipo de cavidade, como cavernas e furnas e este destaque pode ser atribuído às atividades do Grupo Universitário de Pesquisas Espeleológicas (GUPE), que vem desenvolvendo um importante trabalho de inventariação e caracterização do patrimônio espeleológico na região dos Campos Gerais (GUPE, 2017).

Constatou-se que a maioria dos sítios é utilizada com fins turísticos, de forma estrita ou associada a outros usos, como o esportivo. A população em geral frequenta os sítios para recreação e lazer e muitos deles estão atrelados a rios e cachoeiras. Porém, sabe-se que a maior parte desta atividade não é monitorada, elevando o risco de degradação dos locais. Muitas vezes, por falta de informação acabam-se perdendo importantes elementos da geodiversidade, como pinturas rupestres e espeleotemas.

Contudo, o uso turístico dos sítios é apresentado como uma oportunidade de divulgação do patrimônio geológico, a qual pode ser melhor explorada através de atividades didáticas. A interpretação ambiental também é grande aliada à geoconservação e apresenta-se como importante ferramenta que poderia ser implantada nos sítios. Um belo exemplo desta contribuição são os painéis interpretativos presentes nos sítios do Parque Estadual de Vila Velha, instalados pelo Serviço Geológico do Paraná (extinta MINEROPAR).

Por fim, o uso didático é ainda pouco expressivo, comparado ao potencial que os geossítios apresentam. Destaca-se aqui, a importância dos geocientistas em disponibilizar e transmitir informações aos educadores de maneira clara e compreensível. Pela definição de temas (critério "uso potencial de interesse" da Tabela 2), é possível perceber que mais da metade dos sítios se enquadra em mais de um tema de interesse, mostrando a rica diversidade de feições geológicas.

Como grande parte dos sítios localiza-se sobre a Formação Furnas, aspectos da geologia sedimentar são destacados, porém, princípios de estratigrafia, hidrogeologia, paleontologia, geologia estrutural e tectônica apresentam-se com grande relevância na região. Assim como aspectos da espeleologia, de singular expressão na região dos Campos Gerais, que apresenta um sistema cárstico em rochas não carbonáticas. Os elementos da arqueologia foram considerados, por apresentar íntima relação ao patrimônio geológico, e representam importante expressão cultural em consequência da geologia da região. 
Ademais, a categoria Geomorfologia apresenta-se com frequência destacada nos sítios e demonstra o especial contexto geomorfológico da região da APA da Escarpa Devoniana, com contrastes de paisagens, tipos e feições singulares de relevo.

A definição de temas permite auxiliar na proposta de uso dos sítios com enfoque no potencial didático e turístico, com o intuito de direcionar as estratégias de geoconservação subsequentes. Estes temas podem ser trabalhados em atividades didáticas/educativas das geociências e até multidisciplinares, tornando-as mais variadas e interessantes.

\section{CONSIDERAÇÕES FINAIS}

Os sítios de interesse geológico selecionados representam uma amostra consistente da geodiversidade dos Campos Gerais, definida na Área de Proteção Ambiental da Escarpa Devoniana no território do município de Ponta Grossa. Este levantamento de reconhecimento dos sítios faz parte da primeira etapa das estratégias de geoconservação, o inventário de patrimônio geológico. Os dados mostraram a diversidade de categorias temáticas e feições relevantes da geologia que são e que podem ser utilizadas em atividades didáticas, científicas e turísticas. Foram reconhecidos e pré-recomendados tipos de uso para cada sítio, levando em consideração o tipo de feição especial da geodiversidade que cada um deles compreende.

Pôde-se perceber que os sítios da área de estudo são relevantes e podem ser incluídos em um processo de inventariação subsequente. Este processo deve contemplar a avaliação dos sítios a fim de classificá-los pela sua relevância e pela ameaça a que estão submetidos.

Como Crofts e Gordon (2015) apontam, é essencial que a geodiversidade seja levada em consideração no mesmo nível de importância da biodiversidade nas políticas de conservação, reconhecendo o valor dos processos abióticos para proteção da vida. Assim, espera-se que os resultados alcançados colaborem com as próximas estratégias de geoconservação, para então, poder auxiliar no desenvolvimento sustentável da região dos Campos Gerais, com a utilização racional dos recursos naturais da APA da Escarpa Devoniana.

Recomenda-se também que o conhecimento acerca da geodiversidade da APA da Escarpa Devoniana, especialmente em Ponta Grossa, possa ser transmitido à população através de programas de educação ambiental, articulados a práticas sustentáveis de turismo em áreas naturais. Quando se reconhece a importância deste patrimônio na sua história e no seu sustento, a sociedade torna-se ativa nas iniciativas de proteção, sentindo-se pertencente ao local onde vive.

\section{REFERÊNCIAS}

Brasil. Lei n. 9.985, de 18 de julho de 2000. Brasília, DF: Senado, 2000. Recuperado de http:/ /www.planalto. gov.br/ccivil_03/Leis/L9985.htm

Brasil. Constituição da República Federativa do Brasil de 1988. Brasília, DF: Presidência da República, 2017. Recuperado de http:/ / www.stf.jus.br/portal/constituicao/constituicao.asp\#2004 
BRILHA, José (2005). Património Geológico e Geoconservação: a conservação da natureza na sua vertente geológica. Lisboa: Palimage.

Cassol, Maria L., \& Liccardo, Antonio (2013). Patrimônio Geomorfológico do Paraná: A paisagem ao longo da Rota dos Tropeiros. Espaço \& Geografia, 16(2), 579-599.

Crofts, Roger, \& Gordon, John E. (2015). Geoconservation in protected areas. In: Graeme L., Worboys, Michael Lockwood, Ashish Kothari, Sue Feary, Sue, \& Ian Pulsford (Orgs.) Protected Area Governance and Management (pp. 531 - 568). Canberra: ANU Press.

Gray, Murray (2013). Geodiversity: valuing and conserving abiotic nature. (2nd ed.) Chichester: John Wiley \& Sons.

Guimarães, Gilson B., Rocha, Carlos H., Moro, Rosemeri S., \& Liccardo, Antonio (2017). Serviços geossistêmicos e a redução da APA da Escarpa Devoniana. Anais do Simpósio Brasileiro de Patrimônio Geológico e II Encontro Luso-Brasileiro do Patrimônio Geomorfológico e Geoconservação, Ponta Grossa PR, Brasil, 4/2.

Grupo Universitário de Pesquisas Espeleológicas (2017). Patrimônio espeleológico do Parque Nacional dos Campos Gerais - Ações prioritárias para o Manejo e propostas de ampliações da Unidade de Conservação. Ponta Grossa.

Instituto Brasileiro de Geografia e Estatística (2010). Mapas municipais: Ponta Grossa - PR. 2010. Recuperado de https:// mapas.ibge.gov.br/bases-e-referenciais/bases-cartograficas/mapas-municipais

Liccardo, Antonio, \& Piekarz, Gil F. (2017). Tropeirismo e Geodiversidade no Paraná. Ponta Grossa: Estúdio Texto.

Maack, Reinhardt. (1948). Notas preliminares sobre clima, solos e vegetação do Estado do Paraná. Arquivos de Biologia e Tecnologia, 2,102-200.

Melo, Mario S., Moro, Rosemeri, S., Guimarães, Gilson B. (2007). Os Campos Gerais do Paraná. In Mario S. de Melo, Rosemeri S. Moro, \& Gilson B. Guimarães (Orgs.) Patrimônio natural dos Campos Gerais do Paraná. (pp. 17-22). Ponta Grossa: Ed. UEPG.

Minerais do Paraná S.A. (2006a). Mapa Geológico do Estado do Paraná. Escala 1:650.000. Curitiba.

Minerais do Paraná S.A. (2006b). Mapa Geológico da Folha de Ponta Grossa. Escala 1:100.000. Curitiba.

Mochiutti, Nair F., \& Guimarães, Gilson B. (2018). A comunicação para a conservação: o caso do movimento em prol da APA da escarpa Devoniana (Paraná, Brasil). Terræ Didatica, 14(4), 455-462.

Oliveira, Emerson A. (2014). Processos de criação de unidades de conservação na floresta com araucárias: o caso do Parque Nacional dos Campos Gerais, ímpar na história da política ambiental brasileira. Curitiba: Ed UFPR.

Paraná. Decreto $n^{\circ}$ 1.231, de 27 de março de 1992. Curitiba: Governo do Estado, 1992. Recuperado de http://www.iap.pr.gov.br/arquivos/File/Planos_de_Manejo/APA_Escarpa_Devoniana/anexos/1_ Decreto_n_1231_27_marco_1992.pdf

Parellada, Claudia I. (2007). Arqueologia dos Campos Gerais. In: Mário S. Melo, Rosemeri S. Moro, \& Gilson B. Guimarães (Orgs.) Patrimônio Natural dos Campos Gerais do Paraná. (cap 17, pp. 163-170). Ponta Grossa: Ed. UEPG.

Pontes, Henrique S., Massuqueto, Laís L., Guimarães, Gilson B., \& Rocha, Carlos H. (2018). O projeto de lei de redução da APA da Escarpa Devoniana: ameaças à proteção dos campos nativos e cavernas dos Campos Gerais do Paraná, Brasil. Terr@Plural, 12(2), 211-237.

Sharples, Chris (1993). A Methodology for the Identification, of Significant Landforms and Geological Sites for Geoconservation Purposes. Tasmania: Australia: Forestry Commission.

Sharples, Chris (2002). Concepts and Principles of Geoconservation. Recuperado de https://dpipwe.tas.gov. au/Documents/geoconservation.pdf

Souza, Célia R.G., \& Souza, Agenor P. (2002). O Escarpamento Estrutural Furnas, SP/PR - Raro sítio geomorfológico brasileiro. In C. Schobbenhaus, D.A. Campos, E.T. Queiroz, M. Winge, \& M. Berbert-Born (Orgs.) Sítios geológicos e paleotológicos do Brasil. (pp. 299-306). Brasília: DNPM. 
Trzaskos, Barbara, Vesely, Fernando F., \& Rostirolla, Sidnei P. (2006). Eventos tectônicos recorrentes impressos no arcabouço estratigráfico do Grupo Itararé na região de Vila Velha, Estado do Paraná. Boletim Paranaense de Geociências, 58, 89-104.

Wimbledon, William, Andersen, Stephen, Cleal, Chrisopher J., Cowie, John W., Erikstad, Lars, Gonggrijp, Gerald P. et al. (1999). Geological World Heritage: GEOSITES - A global comparative site inventory to enable prioritisation for conservation. Mem Descrittive della Carta Geol D'Italia, 54, 45-60.

Data de submissão: 19/jan./2020

Data de aceite: $07 /$ jun./2020 